\title{
FISIOLOGIA DE MUDAS DE MORANGUEIRO PRODUZIDAS EM SISTEMA CONVENCIONAL E EM VASOS SUSPENSOS ${ }^{1}$
}

\author{
MARCELO FONTANETTI VERDIAL ${ }^{2}$, JOÃOTESSARIOLINETO ${ }^{3}$, KEIGO MINAMI ${ }^{4}$, \\ JOÃO ALEXIO SCARPARE FILHO \\ FABIO VALE SCARPARE ${ }^{3}$, JULIANO FRANCISCO BARELA ${ }^{3}$, \\ JUAN SAAVEDRADELAGUILA ${ }^{3,6}$, RICARDO ALFREDO KLUGE ${ }^{5,6}$
}

RESUMO - A utilização de um sistema adequado para a condução das plantas-matrizes fornecedoras de mudas é de fundamental importância, tanto com a finalidade de favorecer a quantidade de mudas produzidas, como para a qualidade das mesmas; por outro lado, a disponibilidade de mudas em períodos não convencionais de plantio, através da utilização da frigoconservação, possibilita a produção de frutos na entressafra, propiciando maiores ganhos pelos produtores devido aos melhores preços alcançados. Os presentes trabalhos tiveram como objetivos comparar o sistema de produção de mudas de morangueiro convencional com o de produção em vasos suspensos, assim como avaliar a frigoconservação em mudas produzidas em sistema de vasos suspensos. Avaliaram-se a matéria seca, os teores de carboidratos nas mudas e a percentagem de sobrevivência das mesmas após o transplante para local definitivo. No primeiro trabalho, foi utilizado o delineamento inteiramente ao acaso, em esquema fatorial 3x2 (três cultivares: Campinas, Pelican e Guarani; e dois sistemas de produção de mudas), com três repetições de 30 mudas; no segundo trabalho, utilizou-se o delineamento experimental inteiramente ao acaso, com cinco cultivares (Campinas, Dover, Pelican, Sequoia e Sweet Charlie) e nove repetições. Neste último trabalho, após a coleta, as mudas foram acondicionadas em sacos de polietileno e frigoconservadas durante 120 dias em câmara fria $\left(-1 \pm 1^{\circ} \mathrm{C}\right)$. As mudas produzidas em vasos suspensos apresentaram maior percentagem de sobrevivência e maiores teores de carboidratos totais, com resultados semelhantes para as três cultivares estudadas. A frigoconservação de mudas de morangueiro produzidas em sistema de vasos suspensos resultou em baixa percentagem de sobrevivência de mudas no experimento.

Termos para indexação: Fragaria x ananassa Duch., cultivares de morangueiro, produção de mudas, propagação, viveiro.

\section{STRAWBERRY RUNNERS PHISIOLOGY PRODUCED IN CONVENTIONALAND SUSPENDED POTS SYSTEMS}

\begin{abstract}
An appropriate conduction system of the plants that originate the runners has a fundamental importance, in order to favor the amount of produced plants and their quality. On the other hand, through the use of the cold storage, the availability of strawberry runners in the off season periods, makes it possible to produce during the off-season period, so that producers can get better prices for the production. These experiments were conducted in order to compare the conventional strawberry runners' production system with the runner production system in suspended pots, and also to evaluate the cold storage of strawberry runners produced in suspended pots system. It was measured the dry matter and carbohydrates contents in runners and the survival percentage when the runner was transplanted to field production areas. The first experiment was conducted in a completely randomized design, with 3x2 factorial outline (three cultivars: Campinas, Pelican and Guarani; and two runners production systems) with three repetitions of thirty runners each; in the second experiment, it was used the experimental entirely random design, with five strawberry cultivars (Campinas, Dover, Pelican, Sequoia and Sweet Charlie) and nine replicates, in the final experiment. After the selection, the runners were conditioned in polyethylene bags and stored under low temperatures during 120 days $\left(-1 \pm 1^{\circ} \mathrm{C}\right)$. The runners produced in the system of suspended pots showed higher amount of total carbohydrates and higher plant survival rate. The results were similar for the three cultivars. Cold storage of strawberry runners produced in the system of suspended pots resulted in lower percentage of seedlings survival.

Index Terms: Fragaria x ananassa Duch., strawberry cultivars, plant production, propagation, nursery.

${ }^{1}$ (Trabalho 112-08). Recebido em: 07-05-2008. Aceito para publicação em: 03-03-2009.Parte da tese do primeiro autor, apresentada à USP/ESALQ para obtenção do título de Doutor.

${ }^{2}$ Programa de Pós-Graduação em Fitotecnia, ESALQ/USP, Piracicaba-SP, Brasil. E-mail: cruxi@directnet.com.br.

${ }^{3}$ Depto. de Produção Vegetal, ESALQ/USP. In memoriam.

4Depto de Produção Vegetal, ESALQ/USP. kminami@esalq.usp.br, jascarpa@esalq.usp.br, pjchrist@esalq.usp.br, jsaguila@esalq.usp.br

${ }_{5}^{5}$ Depto. de Ciência Biológicas, ESALQ/USP, C.P. 09, CEP 13418-900, Piracicaba-SP. E-mail: rakluge@esalq.usp.br.Bolsista do CNPq. ${ }^{6}$ Bolsista FAPESP.
\end{abstract}




\section{INTRODUÇÃO}

Embora o morangueiro seja fisiologicamente uma espécie perene, os problemas fitossanitários e o próprio desenvolvimento fisiológico da planta limitam que estas sejam mantidas no campo de uma safra para outra, tornando necessário renovar anualmente todo o campo de produção de frutas (Filgueira, 1982; Verdial et al., 2007). As plantas são propagadas comercialmente com a utilização de mudas de estolho, produzidas por plantas-matrizes selecionadas, sendo que o número de mudas pode variar conforme a cultivar, a região de plantio e as condições de cultivo (Passos \& Pires, 1999).

O principal cuidado a ser tomado na fase de produção de mudas é a prevenção da contaminação por pragas e doenças, que podem, posteriormente, comprometer as lavouras de produção de frutas (Assis, 1999).

Além do aspecto fitossanitário, fisiologicamente as mudas devem apresentar potencial produtivo capaz de proporcionar alta taxa de sobrevivência e rápido desenvolvimento inicial das plantas no campo. Para as condições de cultivo em clima temperado, as temperaturas amenas e os dias curtos do início do inverno propiciam o acúmulo de reservas na forma de carboidratos e a dormência das plantas de morangueiro durante o inverno. Na primavera, essas reservas são utilizadas pelas plantas para o início do desenvolvimento vegetativo e reprodutivo. Assim, quanto maior a quantidade de reservas acumuladas, maior será o potencial produtivo das mudas (Rice, 1990).

As mudas de morangueiro produzidas em sistema de vasos suspensos apresentam maiores teores de carboidratos em seus rizomas quando comparadas com mudas produzidas diretamente no solo. Tessarioli Neto (2001) afirma que uma das possíveis explicações para este comportamento está no fato de as mudas produzidas em vasos suspensos não desenvolverem raízes, e desta forma concentrarem os fotossintetizados.

No sistema convencional, a produção de mudas é feita em campo aberto e diretamente no solo. Plantas-matrizes selecionadas, isentas de pragas e doenças, são plantadas em canteiros no espaçamento entre 1 a 2 m entre plantas, onde emitem os estolhos que, ao entrarem em contato com o solo, enraízam, produzindo novas mudas. Estas novas mudas, por sua vez, emitem novos estolhos, que irão originar mais mudas, preenchendo completamente os canteiros. Na época de plantio, as mudas são arrancadas e comercializadas na forma de raiz nua. A produtividade pode chegar a 200 mudas por matriz, com aproveitamento final de cerca de 80\% (Rebelo \& Balardin, 1997).

Devido às características de cultivo e à suscetibilidade do morangueiro a inúmeras pragas e doenças que afetam as raízes e a parte aérea, seu controle deve ser basicamente preventivo e sistemático (Assis, 1999). A manutenção de um viveiro convencional em bom estado fitossanitário é dificultada pelo longo ciclo e principalmente pelas condições adversas ao cultivo do morangueiro (chuvas intensas e altas temperaturas), comuns nos meses de verão. Nessa época, que coincide com o final do ciclo, ocorre a sobreposição e o entrelaçamento das mudas de estolão, formando um microclima bastante favorável ao desenvolvimento de doenças, tornando difícil a aplicação ou mesmo reduzindo a eficiência dos defensivos.

No sistema de vasos suspensos, as plantasmatrizes são cultivadas sob cultivo protegido sobre bancada, de modo que os estolhos não entram em contato com o solo e, consequentemente, não enraízam. A produção de mudas de morangueiro em vasos suspensos, sob cultivo protegido, é tecnicamente viável e, apesar de a quantidade de mudas totais produzidas por planta-matriz ser inferior quando comparada ao sistema convencional no solo, a produtividade por área de cultivo é maior, já que o cultivo é mais adensado (Tessarioli Neto, 2001).

Com respeito à técnica de frigoconservação de mudas de morangueiro, Lieten (2002) e Kamperidou \& Vasilakakis (2006) afirmam que esta técnica possibilita que muitos produtores europeus prolonguem o período produtivo, obtendo uma produção satisfatória depois do pico de produção, quando os preços pagos aos produtores são mais elevados.

Duarte Filho et al. (1999) citam como vantagens do uso desse tipo de muda a possibilidade de aumentar o período de oferta de mudas aptas ao plantio, no momento mais oportuno, conforme o clima e as cultivares. Essa técnica permite ainda, quando necessário, satisfazer as exigências de horas de frio destas mudas.

Nos países onde é comum a frigoconservação de mudas, essas são produzidas diretamente no solo em canteiros. As mudas são arrancadas do viveiro quando se encontram no estádio de latência. Nessa condição, seu conteúdo de substâncias de reservas é adequado, o que favorece sua conservação (Branzanti, 1989).

As condições físicas das plantas no arranquio são determinantes para o sucesso de uma 
longa conservação. As plantas devem ser expostas a um mínimo de horas de frio de acordo com as características de cada cultivar e terem certo nível de dormência antes de serem armazenadas por longos períodos. Estudos demonstraram que somente plantas que acumularam reservas suficientes, podem ser armazenadas (Leiten, 1996). O mesmo autor cita que os melhores armazenamentos e posteriores produções são obtidos com mudas que permanecem encanteiradas, recebendo entre 500 a 800 horas de temperaturas inferiores a $7^{\circ} \mathrm{C}$ e apresentam teores entre 100 a 140 mg de açúcares $\mathrm{g}^{-1}$ de matéria seca. Por ocasião do arranquio das mudas, clima seco e temperaturas baixas (1 a $\left.7^{\circ} \mathrm{C}\right)$ favorecem o processo de armazenagem.

Após o arranquio, é feita uma limpeza, eliminando-se os resíduos de solo aderidos às raízes. A seguir, cortam-se as folhas, cuja presença dificulta a conservação das mudas, além de aumentar o volume por elas ocupado. Já o sistema radicular deve ser mantido intacto o máximo possível, para aproveitar melhor as substâncias de reserva que ele contém (Brazanti, 1989).

É recomendável que as mudas sejam empacotadas de acordo com as dimensões do rizoma. Recomenda-se a utilização de sacos plásticos com espessura de 0,07 mm. Entretanto, não foram observadas diferenças quanto à armazenagem, vigor e produção de frutos para plantas armazenadas em sacos plásticos com espessura entre 0,02 e 0,07 mm (Linden, 1964).

Para longos períodos de armazenamento, a temperatura deve ser mantida na faixa de -1 a $-2^{\circ} \mathrm{C}$, a qual bloqueia as atividades vegetativas e não causa danos aos tecidos das plantas (Brazanti, 1989). Temperaturas abaixo de $-3^{\circ} \mathrm{C}$ podem causar injúria nos tecidos dos rizomas, reduzindo o vigor e a produção (Leiten \& Goffings, 1996).

A utilização de um sistema adequado para a condução das plantas-matrizes fornecedoras de mudas é de fundamental importância, tanto a fim de favorecer a quantidade de mudas produzidas, como a qualidade destas. $\mathrm{O}$ objetivo dos trabalhos foram comparar as mudas de morangueiro produzidas no sistema convencional, com as mudas produzidas no sistema de vasos suspensos quanto ao acúmulo de carboidratos totais e sobrevivência inicial das mesmas, assim como avaliar a viabilidade da utilização do sistema de frigoconservação em mudas de morangueiro produzidas no sistema de vasos suspensos.

\section{MATERIAL E MÉTODOS}

Primeiro Experimento: Teores de carboidratos totais e sobrevivência de mudas de morangueiro produzidas em sistema convencional e em vasos suspensos

Ambos os experimentos foram desenvolvidos no período de 2003-2004, no Departamento de Produção Vegetal da ESALQ/USP, em Piracicaba-SP. As cultivares utilizadas neste primeiro experimento foram: Campinas, Guarani e Pelican, sendo que os sistemas de condução utilizados foram:

a) Sistema de vasos suspensos: as matrizes foram cultivadas em vasos com a capacidade de 5,0 L preenchidos com uma mistura de terra tratada com brometo de metila e substrato comercial GEOMAX II $^{\circledR}$ (elaborado a partir de casca de pínus e vermiculita.), na proporção de 1:1. Os vasos foram mantidos em suportes a $1,50 \mathrm{~m}$ de altura, no espaçamento de $40 \mathrm{~cm}$ entre vasos, dentro de casa de vegetação, coberto com polietileno de baixa densidade, aditivado contra raios ultravioleta; b) Sistema convencional: as matrizes foram cultivadas em canteiros de 0,25 m de altura e 1,0 m de largura, levantados dentro de casa de vegetação, no espaçamento de 1,0 m entre plantas. Os canteiros foram previamente preparados com a mistura de solo e substrato comercial Geomax, na proporção 5:3. Utilizaram-se duas plantas-matrizes por canteiro.

Em ambos os sistemas, foram utilizadas irrigação por gotejamento e fertirrigação, com o uso da fórmula 12-6-12 aplicada na frequência de uma vez por semana. Os demais tratos culturais, incluindo o manejo fitossanitário das plantas-matrizes, foram realizados conforme a necessidade da cultura. Com a emissão dos cordões estoloníferos, na condução do sistema convencional, os estolhos foram mantidos para se desenvolverem sobre os canteiros, permitindo o enraizamento das mudas. No sistema de vasos suspensos, os estolhos foram mantidos na vertical e suspensos.

As mudas de ambos os sistemas foram coletadas e plantadas em bandejas de poliestireno expandido de 128 células preenchidas com vermiculita, sendo levadas para câmara nebulizadora por 15 dias para enraizamento. Após este período, foram transplantadas para os canteiros de produção.

Foram realizadas duas análises da percentagem de sobrevivência de mudas. A primeira ocorreu na ocasião do transplante para os canteiros, sendo analisada a sobrevivência das mudas 15 dias após o plantio nas bandejas de poliestireno expandido. A segunda análise foi realizada após 15 dias do transplante para o local definitivo de cultivo, 
ou seja, 30 dias após o primeiro plantio das mudas.

Para a avaliação da matéria seca $\left(\mathrm{g} \mathrm{kg}^{-1}\right)$, o tecido vegetal foi submetido à secagem em estufa com fluxo de ar a $65^{\circ} \mathrm{C}$, durante $72 \mathrm{~h}$; avaliou-se também o teor de carboidratos totais (mg $100 \mathrm{~mL}^{-1}$ ), seguindo o método descrito por Dubois et al. (1956), as amostras foram retiradas uma única vez por ocasião da coleta das mudas (sistema de vasos suspensos e convencional) e estas foram encaminhadas para o laboratório de análise do Centro de Energia Nuclear na Agricultura (CENA/USP). Cada amostra foi constituída por 30 plantas, das quais foram eliminadas as partes aéreas, permanecendo para a análise apenas os rizomas, no caso das mudas produzidas no sistema de vasos suspensos, e os rizomas e raízes, no caso das mudas produzidas no sistema convencional.

Também, realizou-se a análise das mudas mortas no sistema convencional, na Clínica Fitopatológica do Departamento de Entomologia, Fitopatologia e Zoologia da ESALQ/USP. As análises consistiram na observação com microscópio óptico das amostras, identificando-se visualmente o agente causal da doença, pelas suas estruturas vegetativas ou reprodutivas.

O delineamento experimental foi 0 inteiramente ao acaso, em esquema fatorial 3x2 (três cultivares e dois sistemas de produção de mudas), com três repetições de 30 mudas. Os resultados obtidos foram submetidos à análise de variância (teste F), e as médias, comparadas pelo teste de Tukey, ao nível de 5\% de probabilidade. Os resultados obtidos em valores expressos em percentagem foram transformados para arc-sen $\sqrt{\mathrm{x} / 100}$. Entretanto, as médias apresentadas na tabela de resultados são as originais.

Segundo Experimento: Frigoconservação de mudas de morangueiro produzidas em sistema de vasos suspensos

Utilizaram-se as cultivares Campinas, Dover, Pelican, Sequoia e Sweet Charlie. As plantas-matrizes foram plantadas em vasos de $5 \mathrm{~L}$, preenchidos com o substrato comercial GEOMAX II ${ }^{\circledR}$,formulado a partir de casca de pínus e vermiculita.

Os vasos foram conduzidos sobre uma bancada a $1,5 \mathrm{~m}$ do solo. Foram utilizadas irrigação por gotejamento e fertirrigação, com o uso da fórmula 12-6-12, aplicada na frequência de uma vez por semana. Além disso, foram feitas pulverizações para suplementação de micronutrientes com o adubo Tenso Cocktail ${ }^{\circledR}$, que é composto por B $0,25 \%$, Ca EDTA 2,57\%, Cu EDTA 0,53\%, Fe EDTA 2,10\%, Fe DTPA 1,74\%, Mn EDTA2,57\%, Mo 0,13\% e Zn EDTA
0,53\%. O tratamento fitossanitário foi feito conforme a necessidade.

A coleta das mudas foi realizada aos 167 dias após o plantio das plantas-matrizes. Estas foram classificadas em Extra, Tipo 1, Tipo 2 e Descarte, de acordo com os parâmetros estabelecidos por Ortigoza (1999). Para a experimentação, foram utilizadas apenas as mudas pertencentes às categorias Tipo 1, por representarem a média das mudas obtidas.

Foi realizada a eliminação das folhas das mudas, e estas foram postas para secar à sombra, à temperatura ambiente, durante 24 horas. Após esse período, foi feito o tratamento preventivo das mudas através da imersão em uma solução de Benomil (5\%).

As mudas foram, então, acondicionadas em sacos de polietileno transparentes, com espessura de $0,03 \mathrm{~mm}$, e levadas para câmara fria $\left(-1 \pm 1^{\circ} \mathrm{C}\right)$, onde permaneceram durante 120 dias. Após o período de frigoconservação, as mudas foram retiradas da câmara fria e deixadas na temperatura ambiente do laboratório $\left(22^{\circ} \mathrm{C}\right.$, aproximadamente), durante 6 horas, dentro das próprias embalagens em que foram armazenadas.

Posteriormente, as mudas foram plantadas em bandejas de poliestireno expandido de 128 células, preenchidas com vermiculita, e levadas para câmara úmida, onde permaneceram durante 21 dias para enraizamento. Após este período, as mudas foram transplantadas para vasos plásticos de $250 \mathrm{~mL}$ preenchidos com o mesmo tipo de substrato comercial utilizado na condução das matrizes. Os vasos foram conduzidos em casa de vegetação, cobertos com polietileno de baixa densidade aditivado contra raios ultravioleta, sobre bancada a 1,5 m de altura, e receberam sistema de irrigação e fertirrigação localizada por gotejamento.

Foi analisada a percentagem de sobrevivência de mudas aos 21 dias após o plantio nas bandejas de isopor e 30 dias após o transplante para os vasos.

Utilizou-se o delineamento experimental inteiramente casualizado, sendo cinco cultivares (Campinas, Dover, Pelican, Sequóia e Sweet Charlie), e nove repetições. Cada parcela foi formada por 15 mudas. Os resultados obtidos foram submetidos à análise de variância através do teste F, e as médias dos tratamentos foram comparadas pelo teste de Tukey, ao nível de $5 \%$ de probabilidade. Os resultados obtidos em valores expressos em percentagem foram transformados para arc-sen $\sqrt{\mathrm{x} / 100}$. 


\section{RESULTADOS E DISCUSSÃO}

Primeiro Experimento: Teores de carboidratos totais e sobrevivência de mudas de morangueiro produzidas em sistema convencional e em vasos suspensos

A percentagem de sobrevivência das mudas 15 dias após o plantio, produzidas no sistema de vasos suspensos, foi de $100 \%$ para todas as cultivares (Tabela 1). Já para as mudas produzidas pelo sistema convencional, foram observadas 93,30\%, 80,00\% e $86,60 \%$ para as cultivares Campinas, Guarani e Pelican, respectivamente. Entretanto, a cultivar Campinas não apresentou diferença significativa entre os dois sistemas de cultivo, fato que ocorreu com as outras duas cultivares.

Análises realizadas pelo Departamento de Entomologia, Fitopatologia e Zoologia da ESALQ/ USP demonstraram que a causa da morte de mudas produzidas no sistema convencional foi a infecção pelo fungo Colletotrichum fragariae, comumente conhecida como “chocolate”. O fungo, presente no solo, pode infectar as mudas ainda no viveiro, sendo posteriormente transportadas para o campo (Tanaka et al., 2000).

A produção de mudas em sistema de vasos suspensos provavelmente reduziu a contaminação pelo patógeno, considerando que estas não estiveram em contato com o solo. Soma-se a isso o fato de não ter havido desenvolvimento do sistema radicular, o que proporcionou que as mudas fossem coletadas e plantadas nas bandejas sem danos mecânicos, evitando a contaminação por qualquer patógeno que estivesse no substrato e pudesse penetrar nas plantas través de ferimentos ocasionados no arranquio das mudas. As mudas produzidas no sistema convencional ficaram muito mais suscetíveis à contaminação fúngica devido ao processo de arranquio das mesmas dos canteiros de cultivo, fato que danificou o sistema radicular e favoreceu a penetração do fungo.

Embora a percentagem de sobrevivência das mudas produzidas no sistema de vasos suspensos aos 30 dias tenha decaído em relação à análise aos 15 dias, as mudas produzidas neste sistema ainda assim apresentaram maiores valores quando comparadas com aquelas produzidas no sistema convencional, principalmente ao se observarem os valores obtidos para as cultivares Guarani e Pelican. Assim, é possível que haja diferenças em relação à suscetibilidade das cultivares ao fungo Colletotrichum, o que pode explicar, em parte, as diferenças observadas em relação à sobrevivência das mudas. De maneira semelhante, Verdial (2004) verificou que a diferença da mortalidade entre as cultivares pode ser explicada pelas diferenças genéticas quanto à suscetibilidade de cada cultivar ao fungo Colletotrichum fragariae, agente causal da antracnose, já que este foi o agente causador da diminuição da percentagem de sobrevivência no presente trabalho. Os resultados sugerem que a maior suscetibilidade a este fungo é da cultivar Guarani, e as cultivares Campinas e Pelican apresentaram-se menos suscetíveis.

Em relação à matéria seca, observa-se que não houve diferenças significativas entre as cultivares estudadas em relação ao sistema de produção utilizado (Tabela 2). As três cultivares apresentaram valores muito semelhantes, tanto quando se comparou o sistema de produção adotado, quanto quando se comparam as cultivares entre si dentro de um mesmo sistema de produção.

A utilização do sistema de produção de mudas em vasos suspensos propiciou a formação de mudas com maiores teores de carboidratos totais, quando comparadas com as mudas produzidas no sistema convencional para as três cultivares estudadas (Tabela 3). Este fato se deve à supressão no desenvolvimento das raízes das mudas no sistema de vasos suspensos, sendo que os elementos fotossintetizados que seriam utilizados no desenvolvimento das raízes, ficam acumulados em forma de carboidratos nos rizomas. Já as mudas produzidas no sistema convencional utilizaram estas reservas de carboidratos para o desenvolvimento do sistema radicular. Entretanto, por ocasião do arranquio das mudas, grande parte destas são danificadas e perdidas, principalmente as raízes mais novas e finas. Logo, as mudas produzidas em vasos suspensos apresentaram maior potencial de desenvolvimento quando comparadas àquelas produzidas diretamente no solo.

A ausência de contato com o solo, nas mudas produzidas em sistema de vasos suspensos dentro de casa de vegetação, favoreceu a qualidade fisiológica das mudas pelos maiores teores de carboidratos totais nos rizomas, o que conferiu maior vigor inicial às mudas.

No sistema convencional, as reservas utilizadas na formação das raízes foram praticamente desperdiçadas, uma vez que as mudas produzidas diretamente no solo foram transplantadas na forma de raiz nua, fato que acabou danificando grande parte do sistema radicular, ocasionando estresse na fase de desenvolvimento inicial das mesmas no campo e favorecendo o desenvolvimento da antracnose. 
Segundo Experimento: Frigoconservação de mudas de morangueiro produzidas em sistema de vasos suspensos

Após o período de frigoconservação, houve grande mortalidade de mudas (Tabela 4). Com exceção da cultivar Sweet Charlie, as demais cultivares tiveram menos que $50 \%$ de mudas sobreviventes, sendo que a cultivar Sequoia foi significativamente inferior às demais cultivares. Observa-se ainda que, após 30 dias do transplante para os vasos, a sobrevivência das mudas decresceu mais ainda, sendo que, mesmo aquelas mudas que já haviam iniciado o desenvolvimento, não sobreviveram.

De maneira similar, Hokanson et al. (2004), em pesquisa realizada com mudas de diferentes cultivares de morangueiro e frigoconservadas, também obtiveram uma redução da sobrevivência das mudas após a frigoconservação, sendo esta redução também influenciada pelas cultivares. Por outro lado, Putti et al. (2005) relataram que mudas de morangueiro armazenadas por sete meses a $-2^{\circ} \mathrm{C}$ não apresentaram deterioração.
Segundo Leiten (1996), plantas que serão frigoconservadas devem ser expostas a um mínimo de horas de frio de acordo com as características de cada cultivar e terem certo nível de dormência antes de serem armazenadas por longos períodos. Isto conduz a um acúmulo de reservas no rizoma e nas raízes, com as quais as mudas retomarão o desenvolvimento quando forem plantadas.

Embora mudas produzidas no sistema de vasos suspensos apresentem maiores teores de carboidratos quando comparadas a mudas produzidas convencionalmente (Tessarioli Neto et al., 2003), isto pareceu não ter sido suficiente para o sucesso da frigoconservação no presente trabalho.

Nota-se que a existência de um sistema radicular bem desenvolvido é essencial para que, após o período de armazenamento das mudas, estas possam retornar ao seu desenvolvimento como se tivessem passado por um período natural de vernalização ocasionado pelo inverno.

As condições da muda na ocasião da frigoconservação são essenciais para o sucesso da técnica. Outro fator que pode contribuir para uma baixa capacidade de enraizamento após a frigoconservação das mudas de morangueiro, é a presença e a atividade de microrganismos patogênicos presentes nas mudas (Hokanson et al., 2004).

TABELA 1 - Sistema de condução na sobrevivência de mudas (\%) de morangueiros aos 15 e 30 dias após o plantio. Piracicaba, 2004

\begin{tabular}{ccccc}
\hline \multirow{2}{*}{$\begin{array}{c}\text { Sistemas de } \\
\text { condução }\end{array}$} & Campinas & $\begin{array}{c}\text { Cultivares } \\
\text { Guarani }\end{array}$ & Pelican & \multirow{2}{*}{ CV (\%) } \\
\cline { 2 - 4 } & \multicolumn{3}{c}{$\begin{array}{c}\text { 15 dias } \\
\text { Sobrevivência (\%) }\end{array}$} \\
\hline Vaso Suspenso & $100,00 \mathrm{aA} *$ & $100,00 \mathrm{aA}$ & $100,00 \mathrm{aA}$ & \multirow{2}{*}{5} \\
Convencional & $93,30 \mathrm{aA}$ & $80,00 \mathrm{bB}$ & $86,60 \mathrm{bAB}$ & \\
\hline & & $\mathbf{3 0 d i a s}$ & \multirow{2}{*}{3,5} \\
Vaso Suspenso & $98,90 \mathrm{aA}$ & $96,60 \mathrm{aA}$ & $97,70 \mathrm{aA}$ & \\
\cline { 2 - 4 } Convencional & $88,90 \mathrm{bA}$ & $64,40 \mathrm{bC}$ & $77,40 \mathrm{bB}$ & \\
\hline
\end{tabular}

*Para cada período avaliado, médias seguidas de mesma letra minúscula na coluna e maiúscula na linha não diferem entre si, pelo teste de Tukey, a 5\% de probabilidade. 
TABELA 2 - Matéria seca ( $\mathrm{g} \mathrm{kg}^{-1}$ ) de morangueiros cultivados sob diferentes sistemas de condução. Piracicaba, 2004.

\begin{tabular}{|c|c|c|c|}
\hline \multirow{3}{*}{$\begin{array}{l}\text { Sistemas de } \\
\text { condução }\end{array}$} & \multicolumn{3}{|c|}{ Cultivares } \\
\hline & Campinas & Guarani & Pelican \\
\hline & \multicolumn{3}{|c|}{ Matéria seca $\left(\mathrm{g} \mathrm{kg}^{-1}\right)$} \\
\hline Vaso Suspenso & $920,81 \mathrm{aA} *$ & $923,81 \mathrm{aA}$ & $922,41 \mathrm{aA}$ \\
\hline Convencional & $922,31 \mathrm{aA}$ & $928,09 \mathrm{aA}$ & $923,32 \mathrm{aA}$ \\
\hline $\mathrm{CV}(\%)$ & & 0,25 & \\
\hline
\end{tabular}

*Médias seguidas de mesma letra minúscula na coluna e maiúscula na linha não diferem entre si, pelo teste de Tukey, a 5\% de probabilidade.

TABELA 3 - Teores de carboidratos totais (mg $100 \mathrm{~mL}^{-1}$ ) em morangueiros cultivados em diferentes sistemas de condução. Piracicaba, 2004.

\begin{tabular}{lccc}
\hline \multirow{2}{*}{$\begin{array}{c}\text { Sistemas de } \\
\text { condução }\end{array}$} & \multicolumn{2}{c}{$\begin{array}{c}\text { Cultivares } \\
\text { Campinas }\end{array}$} & $\begin{array}{c}\text { Guarani } \\
\left.\text { carboidratos totais } \mathbf{~ m g ~} \mathbf{~ 1 0 0} \mathbf{~ m L}^{-1}\right)\end{array}$ \\
\cline { 2 - 4 } & \multicolumn{3}{c}{ Pelican } \\
\hline Vaso Suspenso & $247,08 \mathrm{aA}^{*}$ & $243,94 \mathrm{aA}$ & $260,32 \mathrm{aA}$ \\
Convencional & $114,69 \mathrm{bB}$ & $159,73 \mathrm{bA}$ & $72,66 \mathrm{bC}$ \\
$\mathrm{CV}(\%)$ & & 10,7 & \\
\hline
\end{tabular}

*Médias seguidas de mesma letra minúscula na coluna e maiúscula na linha não diferem entre si, pelo teste de Tukey, a 5\% de probabilidade.

TABELA 4 - Percentagem de sobrevivência de mudas de morangueiro frigoconservadas após 21 dias de plantio e após 30 dias do transplante para os vasos. Piracicaba, 2004.

\begin{tabular}{lcc}
\hline CULTIVARES & $\begin{array}{c}\text { sobrevivência após 21 } \\
\text { dias do plantio nas } \\
\text { bandejas (\%) }\end{array}$ & $\begin{array}{c}\text { sobrevivência após 30 } \\
\text { dias do transplante (\%) }\end{array}$ \\
\hline Campinas & $47,1 \mathrm{a}$ & $33,0 \mathrm{bc}$ \\
Dover & $49,2 \mathrm{a}$ & $40,4 \mathrm{ab}$ \\
Sweet Charlie & $54,4 \mathrm{a}$ & $47,6 \mathrm{a}$ \\
Sequoia & $30,7 \mathrm{~b}$ & $14,5 \mathrm{~d}$ \\
Pelican & $45,5 \mathrm{a}$ & $26,3 \mathrm{c}$ \\
\hline CV (\%) & 23,1 & 26,9 \\
\hline
\end{tabular}

Médias seguidas de mesma letra minúscula na coluna não diferem entre si, pelo teste de Tukey, a 5\% de probabilidade.

\section{CONCLUSÕES}

1-A produção de mudas de morangueiro em sistema de vasos suspensos propiciou a produção de mudas com maiores teores de carboidratos totais, melhor qualidade fitossanitária e maior percentagem de sobrevivência no campo do que as mudas produzidas no sistema convencional.

2-A frigoconservação durante o período considerado das mudas de morangueiro produzidas em sistema de vasos suspensos nas condições climáticas de Piracicaba-SP, mostrou-se inviável devido à alta taxa de mortalidade. Assim, a tecnologia empregada para o armazenamento de mudas de morangueiro através da frigoconservação descrita na literatura não se aplica às mudas produzidas em sistema de vasos suspensos em condições tropicais de cultivo. 


\section{REFERÊNCIAS}

ASSIS, M. Sanidade do material vegetativo na produção de mudas de morangueiro, In: DUARTE FILHO, J. et al. Morango: tecnologia de produção e processamento. Pouso Alegre: Editora Suprema, 1999. p.65-71.

BRANZANTI, E.C. La fresa. Madrid: Mundi-Prensa, 1989. 386p.

DUARTE FILHO, J.; ANTUNES, L.E.C.; CUNHA, R.J.P.; ALUARENGA, D.A.; PEREIRA, G.E.Aspectos do florescimento e técnicas empregadas objetivando a produção precoce em morangueiros. Informe Agropecuário, Belo Horizonte, v.20, n.189, p.30-35, 1999.

DUBOIS, M.; GILES,K.A.; HAMILTON,J.K.; REBERS,P.A.; SMITH, F. Colorimetric method for determination of sugars and related substances. Analytical Chemistry, Washington, v.28, p.350, 1956.

FILGUEIRA, F.A.R. Manual de olericultura: cultura e comercialização de hortaliças. 2. ed. São Paulo: Agronômica Ceres, 1982. 2v. 357p.

HOKANSON, S.C.; TAKEDA, F.; ENNS, J.M.; BLACK, B.L. Influence of plant storage duration on Strawberry runner tip viability and field performance. HortScience, Alexandraia, v.39, n.7, p.1596-1600, 2004.

KAMPERIDOU, I.; VASILAKAKIS, M. Effect of propagation on some quality attributes of strawberry fruit (Fragaria x ananassa, var. Selva). Scientia Horticulturae, Amsterdan, v.107, p.137-142, 2006.

LEITEN, F. Relationship of digging date, chilling and root carbohydrate content to storability of strawbery plants. Acta Horticulturae, Wageningen, v.439, n.1, p.623-625, 1996.

LEITEN, F.; GOFFINGS, G. Effects of temperature and controlled atmosphere on cold storage of strawbwrry plants. Acta Horticulturae, Wageningen, v.439, n.1, p.445-448, 1996.

LIETEN, P. The use of cold stored plant material in central Europe. Proceedings of $4^{\text {th }}$ Int. Strawberry Symposium. Acta Horticulturae, Wageningen, v.567, n.2, p.553-559, 2002.

LINDEN, R. La conservation des stolons de fraisiers. Fruit Belge, Namur, v.32, p.76-78, 1964.

ORTIGOZA, L.E.R. Comportamento de diferentes cultivares de morangueiro na produção de mudas de campo. 1999. 43f. Dissertação (Mestrado em Fitotecnia) - Escola Superior de Agricultura "Luiz de Queiroz”, Universidade de São Paulo, Piracicaba, 1999.

PASSOS, F.A.; PIRES, R.M.C. Técnicas culturais utilizadas na cultura do morangueiro. Informe Agropecuário, Belo Horizonte, v.20, n.198, p.43-51, 1999.

PUTTI, G.L.; RAGEAU, R.; BONHOMME, M.; LEITE, G.B.; PETEL,G. Evolução do estado fisiológico da parte aérea do morangueiro durante a armazenagem em câmara frigorífica. Revista Brasileira de Fruticultura, Jaboticabal, v.27, n.2, p.310-313, 2005.

REBELO J.A.; BALARDIN, R.S. A cultura do morangueiro. 3.ed. Florianópolis: EPAGRI, 1997.44p. (Boletim Técnico, 46).

RICE JR., R.P. Effects of cultivar and environmental interations on runner prouction, fruit yield, and harvest timing of strwbery (Fragaria $x$ ananassa Duch.). Acta Horticulturae, Wageningen, n.279, p.327-332, 1990.

TANAKA M.A.S.; BETTI, J.A.; PASSOS, F.A. Manejo integrado de pragas e doenças do morangueiro. São Paulo: Secretaria de Agricultura e Abastecimento, 2000. v.5, 61p. (Manual Técnico, série especial).

TESSARIOLI NETO, J. Produção de mudas de morangueiro (Fragaria $x$ ananassa Duch.) sob cultivo protegido. 2001. 75f. Tese (Livre-Docência)Escola Superior de Agricultura "Luiz de Queiroz”, Universidade de São Paulo, Piracicaba, 2001.

TESSARIOLI NETO, J.; VERDIAL, M. F.; REIS, F. A. M. Acúmulo de carboidratos em mudas de morangueiro produzidas em sistema convencional e em vasos suspensos. Horticultura Brasileira, Brasília, v.21, n.2, p.284, 2003. Suplemento.

VERDIAL, M.F. Frigoconservação e vernalização de mudas de morangueiro (Fragaria $x$ ananassa Duch.) produzidas em sistema de vasos suspensos. 2004. 71f. Tese (Doutorado) - Escola Superior de Agricultura “Luiz de Queiroz”, Universidade de São Paulo, Piracicaba, 2004.

VERDIAL, M.F.; TESSARIOLI NETO, J.; MINAMI, K.; SCARPARE FILHO, J.A.; CHRISTOFFOLETI, P.J.; SCARPARE, F.V.; BARELA, J.F.; SAAVEDRA DELAGUILA, J.; KLUGE, R.A. Vernalização em cinco cultivares de morangueiro. Ciência Rural, Santa Maria, v.37, n.4, p.976-981, 2007. 